\title{
Analysis of the Influence Parameters on the Support Structure Stiffness of Large Radial-Axial Bearings
}

\author{
Spasoje Trifković1 - Nebojša Zdravković2 - Milomir Gašić2 - Mile Savković2 - Goran Marković2,* \\ ${ }^{1}$ University of East Sarajevo, Faculty of Mechanical Engineering, Bosnia and Herzegovina \\ 2 University of Kragujevac, Faculty of Mechanical and Civil Engineering in Kraljevo, Serbia
}

In certain types of crane and earth-moving machinery, such as portal cranes, loaders and excavators, the transfer of loads to crane tracks or the terrain is accomplished by means of undercarriage frames composed of box-like girders. The hypothesis that all four supports of the undercarriage frame do not lie in the horizontal plane is the basis for the formation of a calculation model. This paper analyses the influence of geometric parameters of box-like girders on the magnitude of additional forces at the supports of those frames when one of the supports is raised or lowered relative to the horizontal plane for the size $\Delta$. Theoretical dependences between moments of inertia and stiffness under bending and torsion of those girders were thus established. Obtained relations leads to more concise forms of expressions for influential coefficients in Maxwell-Mohr integrals and simplifies optimization methods in the design of support structures. With experimental verification of the results, the influences of geometric parameters on the stiffness of the support structure are confirmed, and preconditions are created for further analysis of the connection made by large diameter bearings.

Keywords: support structure, large diameter bearing, box-like girders, geometrical parameters, stiffness, experimental verification

Highlights

- A calculation method was created for determination of additional forces in the undercarriage frame supports in relation to its geometric parameters and initiative deflection in one support.

- $\quad$ The dependence between the ratio of moments of inertia for bending and torsion and the height-width ratio of the box-like cross-section was established.

- Dependences were confirmed using the measurement results on the models of undercarriage frames of different geometrical values.

- $\quad$ The obtained results lead, to a great extent, to the simplification of optimization methods in the design of carrying structures with box-like girders, and they are the precondition for further analysis of proper functioning of the connection realized by large diameter bearings.

\section{O INTRODUCTION}

The connections between the undercarriage and upper structure in certain types of cranes and earthmoving machines are accomplished by large diameter bearings, considering the influence of various operational and structural requirements. The purpose of analysing the functioning of these connections in real conditions is to provide an adequate distribution of loads, as well as the reliable and long-lasting operation of large bearings. The main research topics about large slewing bearings are related to empirical investigations and computational analyses of the failure mechanisms and the determination of internal contact load distributions and load capacity [1]. Generally, authors use both the analytical and the numerical approach for solving these problems. The detailed review of the former analytical approaches is presented in [2] and [3], where both articles offer the calculation models for determination of the contact angle and the carrying capacity of a four contact-point ball bearing.
Modern approaches for computing the load capacity of slewing bearings are based on the finite element method (FEM). These computational methods ([4] and [5]) include the most influential parameters, such as the raceway/ring deformations, non-parallel ring displacements, and bearing clearances. In general, it has been shown that all of these parameters have a significant role when determining the load capacity of large slewing bearings. Olave et al. [6] used two different ways for obtaining the force distribution in four contact-point slewing bearings (FEM analysis and new calculation procedure considering the effect of the structure's elasticity). This analysis shows that the flexibility of the structures must be taken into account during the calculation of load distribution. Authors in [7] outline a procedure for the determination of the interferences between balls and raceways in four contact-point slewing bearings due to the manufacturing errors. Therefore, an inadequate hardened raceway depth can cause raceway failure. In contrast, an excessively large hardened raceway depth can increase the overall vibration and production cost. 
Authors in [8] analysed a three-row roller slewing bearing with a hardened raceway, by using a nonlinear spring instead of a solid roller, to quickly obtain the maximum contact load.

Another direction of research leads to the analysis of influences of the undercarriage frame on the slewing bearing operation. Many researchers have found the stiffness of the supporting structure to be a crucial constructional problem of large slewing mechanisms ([9] and [10]). The supporting structure and the bolted connections cannot be ignored when the load distribution and carrying capacity of a slewing bearing are analysed. The effects of supporting structure, bolts number and preload, ball-race contact truncation and bolt-hole backlash on the carrying capacity of the slewing bearing are analysed in [11]. Results show that the fatigue life and carrying capacity of the slewing bearing can be enhanced by appropriately decreasing the supporting structure stiffness. Duval et al. [12] proposed fatigue analysis, taking into account the complex multiaxial stress state and the gradient of material properties, due to the surface treatment of the tracks (induction hardened parts). A method for the fatigue testing of the raceway by using a small sample is presented in [13]. Recent research [14] is directed to additional factors that influence the position of the resultant force exerted by the superstructure on the undercarriage (large excavation or loading forces, the mass of the transported material and ground inclination). Smaller deviations of the centre of the gravity accelerate the wear of the bearing raceway and cause overloading of the bolts that connect the bearing to the supporting elements. For that purpose, the experimental determination of the centre of the gravity of opencast mining machines is presented in [15].

There are not many publications describing the influences of geometrical parameters of the large diameter bearing support structure on its stiffness. Namely, the clearance between one of the undercarriage frame supports and the crane track or the terrain may occur. Hence, the problem of missing contact can appear due to irregularities on the base or, more rarely, errors that arise during manufacturing. As a consequence, there is a redistribution of vertical forces at the supports and the deformation of the carrying structure during exploitation.

In this paper, attention is directed to the creation of a calculation model, used to define theoretical dependences between the geometrical parameters of box-like girders and the magnitude of additional forces at the undercarriage frame supports. Specifically, the magnitude of additional forces directly influences the functioning of large diameter bearings. The research of those relations was carried out to define such stiffness that the deformation of the support surface of the bearing would not exceed recommended values. Along with the experimental verification of the obtained theoretical results, the preconditions for significant simplification of some optimization methods [16] in the design of carrying structures with box-like girders were established.

After the introductory notes and the overview of previous investigations, the calculation model of the undercarriage frame is presented. The next section deals with the box-like section with constant thickness. Firstly, after some approximations, the theoretical dependence between the ratio of bending and torsional stiffness and the height-width ratio of the section is defined. Consequently, after solving the canonical equations and by using MATLAB curvefitting tools, the influences of change in girders' height-width ratios and change of structure lengths on the additional forces are determined. After this, an experimental verification on a laboratory model of the undercarriage frame is presented. The conclusion section gives the final remarks and the directions for further research.

\section{CREATION OF THE CALCULATION MODEL}

In the carrying structures of loader bridges, portal cranes and excavators, clearance $\Delta$ may occur under one of the supports of undercarriage frames (e.g., under the support C) in relation to the crane track or terrain (Fig. 1). The basic calculation model obtains the form as in Fig. 2b, where we take the reactions $X_{1}$ as the force redundant at $\mathrm{D}$ and redundant reactions $X_{2}$ and $X_{3}$ by cutting the structure at an arbitrary interior point. The flexibility coefficients are now interpreted as the relative displacements of the adjacent crosssection.

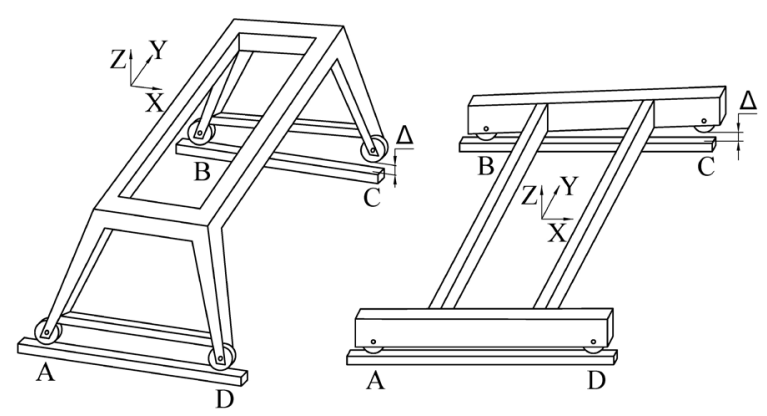

Fig. 1. Undercarriage frames of crane and earth-moving machines 
The resulting displacements of the primary structure due to the external loading and redundant reactions are expressed as:

$$
\sum_{j=1}^{3} \delta_{i j} X_{j}+\Delta_{i}=0, \quad i=1,2,3,
$$

where $\delta_{i j}$ is the flexibility coefficients, $X_{j}$ the unknown forces and moment, $\Delta_{i}$ the displacement at $i$ due to the external loading in the direction of the restraint at $i$.

The flexibility coefficients $\delta_{i j}$ are determined by the Maxwell-Mohr integral [17]:

$$
\begin{aligned}
\delta_{i j} & =\int_{l} \frac{M_{t i} M_{t j}}{G I_{t}} d z+\int_{l} \frac{M_{x i} M_{x j}}{E I_{x}} d z+\int_{l} \frac{M_{y i} M_{y j}}{E I_{y}} d z+ \\
& +\int_{l} \frac{N_{i} N_{j}}{E A} d z+\int_{l} \frac{K_{x} Q_{x i} Q_{x j}}{G A} d z+\int_{l} \frac{K_{y} Q_{y i} Q_{y j}}{G A} d z .
\end{aligned}
$$

For the considered case (no axial forces nor horizontal bending, the influence of shear forces is neglected), $\delta_{i j}$ has the form:

$$
\delta_{i j}=\int_{l} \frac{M_{t i} M_{t j}}{G I_{t}} d z+\int_{l} \frac{M_{x i} M_{x j}}{E I_{x}} d z
$$
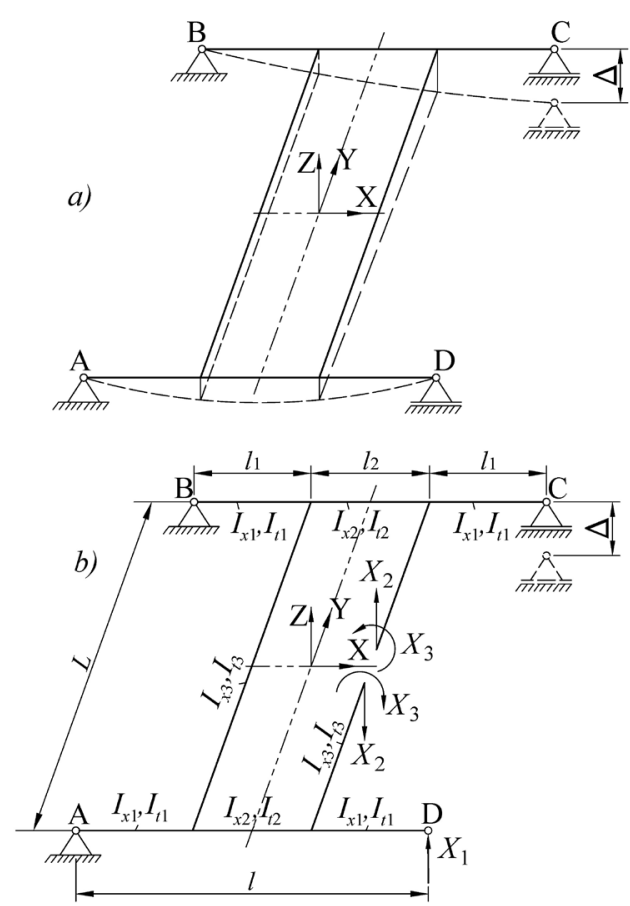

Fig. 2. Schematic presentation of the undercarriage frame: a) position of the undercarriage frame with the clearance $\Delta$ at the support $\mathrm{C}$; b) calculation model of the frame with the unknowns $\mathrm{X}_{1}, \mathrm{X}_{2}$ and $\mathrm{X}_{3}$

Integration over the entire contour results in:

$$
\begin{aligned}
& \delta_{11}=\frac{4 l_{1}^{3}}{3 E I_{x 1}}+2 \frac{l_{1} l_{2}^{2}}{E I_{x 2}}\left(1+l_{1} / l_{2}+l_{2} / 3 l_{1}\right)+\frac{l_{2}^{2} L}{G I_{t 2}}, \\
& \delta_{22}=\frac{2 l_{2}^{3}}{3 E I_{x 2}}+\frac{L^{3}}{6 E I_{x 3}}+\frac{l_{2} L^{2}}{2 G I_{t 2}}, \\
& \delta_{33}=\frac{2 l_{2}}{E I_{x 2}}+\frac{2 L}{G I_{t 3}}, \quad \delta_{12}=\frac{l_{2}^{2}\left(3 l_{1}+2 l_{2}\right)}{3 E I_{x 2}}, \\
& \delta_{13}=-\frac{l_{2}\left(2 l_{1}+l_{2}\right)}{E I_{x 2}}-\frac{l_{2} L}{G I_{t 3}}, \quad \delta_{23}=-\frac{l_{2}^{2}}{E I_{x 2}},
\end{aligned}
$$

As can be seen from Eq. (4), bending stiffness $(E I)$ and torsional stiffness $\left(G I_{t}\right)$ figure in some of them. By establishing the theoretical dependence between them, Eq. (4) would obtain a more concise form, which would simplify the analysis below.

\section{THEORETICAL DEPENDENCE OF THE RATIO OF BENDING AND TORSIONAL STIFFNESS OF BOX-LIKE GIRDERS}

The moment of inertia of the box-like cross-section (Fig. 3) with constant thicknesses of horizontal and vertical plates $\delta$, for the axis $x$, is defined by the expression:

$$
I_{x}=2 \frac{\delta(h+\delta)^{3}}{12}+2\left[\frac{(b-\delta) \delta^{3}}{12}+\delta(b-\delta) \frac{h^{2}}{4}\right] .
$$

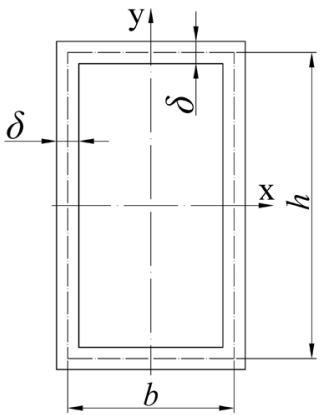

Fig. 3. Section of the box-like girder with constant plate thickness

Further, if the height of the box-like girder $h$ is expressed through the width $b$, i.e., if the coefficient $k=h / b$ is introduced, by neglecting the members in which $\delta^{3}$ and $\delta^{4}(\delta<<b ; \delta<<h)$, then the expression for the moment of inertia of the cross-section of the box-like girder Eq. (5) can be written in the form:

$$
I_{x}^{\prime}=\frac{k^{2} \delta b^{3}}{6}(k+3) \text {. }
$$


Since the thicknesses of the plates are equal, the torsional moment of inertia can be written in the following form:

$$
I_{t}=\frac{2 b^{2} h^{2} \delta^{2}}{b \delta+h \delta}=\frac{2 k^{2} \delta b^{3}}{1+k} .
$$

Now, the following relation can be formed:

$$
\frac{I_{x}^{\prime}}{I_{t}}=i^{\prime}=\frac{k^{2}+4 k+3}{12} \text {. }
$$

The same relation with the exact value for $I_{x}$ (Eq. (5)) is designated as $i=I_{x} / I_{t}$. Eq. (8) has a parabola shape. Since the real values for $k$ are within the interval between 1 and 3, it can be approximated with a linear polynomial which gives the lowest deviations. This was obtained with the MATLAB software package and its incorporated tools for approximation. A set of arranged pairs $(k, i)$ is defined with a step 0.5 for $k$ (Table 1). For the given first degree of the polynomial, the following is obtained:

$$
i=i(k)=0.667 k-0.048 \text {. }
$$

The relative deviations at the corresponding points during the approximation by a first degree polynomial are also given in Table 1.

Table 1. Set of arranged pairs $(k, i)$

\begin{tabular}{cccc}
\hline Reference point & $k$ & $i=i(k)$ & Approximation error [\%] \\
\hline 1 & 1.0 & 0.667 & -6.291 \\
\hline 2 & 1.5 & 0.937 & 1.481 \\
\hline 3 & 2.0 & 1.250 & 2.778 \\
\hline 4 & 2.5 & 1.604 & 0.866 \\
\hline 5 & 3.0 & 2.00 & -2.430 \\
\hline
\end{tabular}

By neglecting the free member due to its small value, Eq. (9) obtains the following form:

$$
i=i(k) \approx \frac{2}{3} k .
$$

The relative error made by this transformation does not exceed $6.5 \%$. The approximation is confirmed for the cross section of the real box-like girders with characteristics: $b=30 \mathrm{~cm} ; \delta=0.8 \mathrm{~cm}$ and $1.0 \mathrm{~cm}$ and $k=1.0,1.5,2.0,2.5,3.0$ (Table 2).

It can be shown that even for larger plate thicknesses (over $1 \mathrm{~cm}$ ), the percentage deviation from exact values of the ratio does not exceed $8 \%$. By analysing the values from Table 2 , it can be concluded that the approximation is acceptable not only for practical but also for theoretical usage.

Regarding the theoretical dependence (Eq. (10)), it is also possible to establish the approximate dependence between bending stiffness $\left(E I_{x}\right)$ and torsional stiffness $\left(G I_{t}\right)$ of the box-like girder:

$$
\frac{E I_{x}}{G I_{t}}=\frac{2(1+v) G I_{x}}{G I_{t}}=\frac{2(1+0.3) I_{x}}{I_{t}} \approx \sqrt{3} k
$$

The defined ratio of the bending stiffness and the torsional stiffness of box-like girders (Eq. (11)) is important for the optimization of the crane and earthmoving machinery carrying structures. It enables creating the compact analytical models, suitable for application of the optimization methods, which provide the solution with increased bending and torsional stiffness, along with the mass reduction.

\subsection{Additional Forces at the Supports of Undercarriage Frames}

The solution of the canonical equations (Eq. (1))

\begin{tabular}{|c|c|c|c|c|c|c|c|c|c|}
\hline \multirow{3}{*}{$\delta[\mathrm{cm}]$} & \multirow{3}{*}{$k$} & \multicolumn{3}{|c|}{ Exact values } & \multicolumn{3}{|c|}{ Approximate values } & \multirow{2}{*}{$2 k / 3$} & \multirow{2}{*}{$p[\%]$} \\
\hline & & $I_{x}$ & $I_{t}$ & $i=I_{x} / I_{t}$ & $I_{x}{ }^{\prime}$ & $I_{x}{ }^{\prime} / I_{x}$ & $i^{\prime}=I_{x}{ }^{\prime} / I_{t}$ & & \\
\hline & & 1 & 2 & 3 & 4 & 5 & 6 & 7 & 8 \\
\hline \multirow{5}{*}{0.8} & 1.0 & 536.7 & 800.0 & 0.671 & 533.3 & 0.993 & 0.666 & 0.666 & 0.64 \\
\hline & 1.5 & 2354.7 & 1440.0 & 0.940 & 1350.0 & 0.996 & 1.250 & 1.000 & -6.29 \\
\hline & 2.0 & 2672.6 & 2133.3 & 1.252 & 2666.6 & 0.997 & 1.250 & 1.333 & -6.42 \\
\hline & 2.5 & 4590.6 & 2857.1 & 1.606 & 4583.3 & 0.998 & 1.600 & 1.666 & -3.73 \\
\hline & 3.0 & 7208.5 & 3600.0 & 2.002 & 7200.0 & 0.998 & 2.000 & 2.000 & 0.11 \\
\hline \multirow{5}{*}{1.0} & 1.0 & 673.3 & 1000.0 & 0.673 & 666.6 & 0.990 & 0.666 & 0.666 & 0.99 \\
\hline & 1.5 & 1696.6 & 1800.0 & 0.942 & 1687.5 & 0.994 & 0.937 & 1.000 & -6.09 \\
\hline & 2.0 & 3345.0 & 2666.6 & 1.254 & 3333.3 & 0.996 & 1.250 & 1.333 & -6.29 \\
\hline & 2.5 & 5473.3 & 3571.4 & 1.608 & 5729.1 & 0.997 & 1.604 & 1.666 & -3.64 \\
\hline & 3.0 & 9016.6 & 4500.0 & 2.000 & 9000.0 & 0.998 & 2.000 & 2.000 & 0.18 \\
\hline
\end{tabular}
contains the value of the additional force $X_{1}$ at support $\mathrm{D}$, caused by the lowering of the support $\mathrm{C}$ by a value $\Delta$ (Fig. 2).

Table 2. Exact and approximate ratio values 
At the same time, due to the symmetry, the reactions at the supports $\mathrm{A}$ and $\mathrm{C}$ will be decreased by the same value $X_{1}$.

In real structures, girders 1 and 2 (Fig. 2) are identical, i.e., $I_{x 1}=I_{x 2}, I_{t 1}=I_{t 2}$. Further on, the bending moment of inertia of the girder 3 can be expressed in relation to the bending moment of inertia of the girder 2 by coefficient $\varepsilon: I_{x 3}=\varepsilon I_{x 2}$. Considering Eq. (10) and the same value of parameter $k$ for the whole structure, it is also $I_{t 3}=\varepsilon I_{t 2}$.

Considering Eq. (11) and having in mind that $\Delta_{1}=-\Delta$ and $\Delta_{2}=\Delta_{3}=0$, the canonical Eqs. (1) obtain the following form:

$$
\begin{aligned}
& {\left[\frac{4 l_{1}^{3}}{3}+2 l_{1} l_{2}^{2}\left(1+\frac{l_{1}}{l_{2}}+\frac{l_{2}}{3 l_{1}}\right)+l_{2}^{2} L \sqrt{3} k\right] \frac{X_{1}}{\Delta E I_{x 2}}+} \\
& +\left[\frac{l_{2}^{2}\left(3 l_{1}+2 l_{2}\right)}{3}\right] \frac{X_{2}}{\Delta E I_{x 2}}-\left[l_{2}\left(2 l_{1}+l_{2}\right)+\frac{\sqrt{3} l_{2} L k}{\varepsilon}\right] \frac{X_{3}}{\Delta E I_{x 2}}=1, \\
& {\left[\frac{l_{2}^{2}\left(3 l_{1}+2 l_{2}\right)}{3}\right] \frac{X_{1}}{\Delta E I_{x 2}}+\left[\frac{2 l_{2}^{3}}{3}+\frac{L^{3}}{6 \varepsilon}+\frac{l_{2} L^{2} \sqrt{3} k}{2}\right] \frac{X_{2}}{\Delta E I_{x 2}}-} \\
& -\left[l_{2}^{2}\right] \frac{X_{3}}{\Delta E I_{x 2}}=0, \\
& {\left[l_{2}\left(2 l_{1}+l_{2}\right)+\frac{\sqrt{3} l_{2} L k}{\varepsilon}\right] \frac{X_{1}}{\Delta E I_{x 2}}-\left[l_{2}^{2}\right] \frac{X_{2}}{\Delta E I_{x 2}}+} \\
& +\left[2 l_{2}+\frac{2 \sqrt{3} L k}{\varepsilon}\right] \frac{X_{3}}{\Delta E I_{x 2}}=0,
\end{aligned}
$$

The further analysis is carried out for the real undercarriage frame structures (Fig. 4), with changeable lengths $(L=4.0 \mathrm{~m}, 4,5 \mathrm{~m}, 5.0 \mathrm{~m}, 5.5 \mathrm{~m}$, $6.0 \mathrm{~m})$ and values of coefficients $\varepsilon(1.0,1.5,2.0)$ and $k$ (range between 1 and 3).

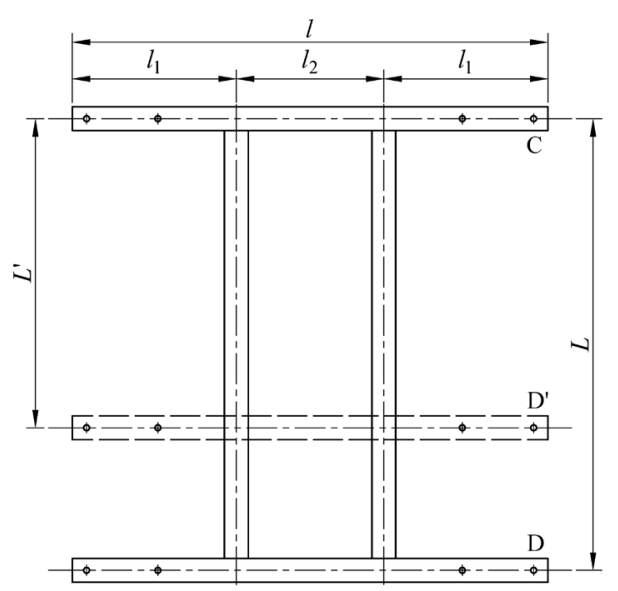

Fig. 4. Geometrical parameters of undercarriage frames

Solving of Eqs. (12) leads to the values of additional forces $X_{1(j)}$ and $X_{1(i)}$, whose ratio will be investigated due to the change of length $L$ and mentioned parameters.

Calculated solutions of Eqs. (12) for all cases are given in Table 3 in the form $\left(X_{1} / \Delta E I_{x 2}\right) 10^{3}$, based on which the further numerical analyses are conducted. Firstly, the results shown in Table 3 are used to establish the dependence of ratio $X_{1(j)} / X_{1(i)}$ as a function of the ratio $k_{j} / k_{i}$, and secondly to establish dependence of ratio $X_{1(j)} / X_{1(i)}$ as a function of the ratio of the length $L_{i} / L_{j}$.

Within the investigation with changeable $k$, the ratio between additional force reactions for arbitrary cases $j$ and $i$, regarding Eq. (6), is calculated as:

$$
\frac{X_{1(j)}}{X_{1(i)}}=\frac{X_{1}\left(k_{j}\right)}{X_{1}\left(k_{i}\right)}=\frac{\left[\frac{X_{1(j)}}{\Delta E I_{x 2}\left(k_{j}\right)}\right]_{t a b}}{\left[\frac{X_{1(i)}}{\Delta E I_{x 2}\left(k_{i}\right)}\right]_{t a b}} \cdot \frac{k_{j}^{2}\left(k_{j}+3\right)}{k_{i}^{2}\left(k_{i}+3\right)} .
$$

For the second analysis with changeable length, there was no need for such conversion since coefficient $k$ is the same for cases $j$ and $i$, so the ratio of forces is calculated only by the values from Table 3 .

After numerical analysis conducted in MATLAB software and its curve fitting tools, with the neglected influence of coefficient $\varepsilon$, the following dependences were established:

$$
\begin{gathered}
\frac{X_{1(j)}}{X_{1(i)}} \approx\left(\frac{k_{j}}{k_{i}}\right)^{\sqrt{3}} . \\
\frac{X_{1(j)}}{X_{1(i)}}=\frac{X_{1}\left(L_{j}\right)}{X_{1}\left(L_{i}\right)} \approx\left(\frac{L_{i}}{L_{j}}\right)^{0.6739} .
\end{gathered}
$$

\section{EXPERIMENTAL ANALYSIS}

Experimental analysis was carried out in the laboratory of the Centre for Construction and Transportation Machinery at the Faculty of Mechanical and Civil Engineering in Kraljevo, Serbia. The primary measurements in the experiment were the additional forces at the support $\mathrm{D}$ at different deflections $\Delta$ at the support $\mathrm{C}$, for two undercarriage frame models (Fig. 4). All activities during the test should be in the field of elastic material behaviour.

\subsection{Object of Testing}

The testing models of undercarriage frames consist of square pipes of the unique wall thickness of $2.8 \mathrm{~mm}$, with the cross sections $b \times h=60 \mathrm{~mm} \times 60 \mathrm{~mm}$ and $b$ 
Table 3. Solutions of canonical Eqs. (12) for different parameters

\begin{tabular}{|c|c|c|c|c|c|c|c|c|c|c|c|c|c|c|c|}
\hline \multirow{3}{*}{$k$} & \multicolumn{15}{|c|}{$\left(X_{1} / \Delta E I_{x 2}\right) 10^{3}$} \\
\hline & & $L=4.0$ & & & $L=4.5$ & & & $L=5.0$ & & & $L=5.5$ & & & $L=6.0$ & \\
\hline & & $\varepsilon=1.5$ & $\varepsilon=2.0$ & $\varepsilon=1.0$ & $\varepsilon=1.5$ & & $\varepsilon=1.0$ & $\varepsilon=1.5$ & & & $\varepsilon=1.5$ & & & $\varepsilon=1.5$ & 2.0 \\
\hline 1.000 & 7.068 & 4.745 & 3.914 & 5.485 & 3.087 & & 24.140 & 21.684 & 0.780 & 22.972 & 20.475 & & & & \\
\hline 1.100 & & 71 & 90 & & & & & 519 & & & & & & 31 & \\
\hline & & & & & & & & & & & & & & 11 & \\
\hline 250 & & 21.8 & 88 & & & & & 19.012 & & & & & & 31 & \\
\hline 300 & & 21. & & & & & & 563 & & & & & & 4 & \\
\hline 00 & & & & & & & & 31 & & & & & & & \\
\hline 500 & & & & & & & & 977 & & & & & & 47 & \\
\hline 600 & & & & & & & & 289 & & & & & & 3 & \\
\hline & & & & & & & & & & & & & & & \\
\hline & & & & & & & & & & & & & & & \\
\hline 1.800 & & & & & & & 345 & 079 & & & & & & 99 & \\
\hline 00 & & & & & & & & & & & & & & & \\
\hline & & & & & & & & & & & & & & & \\
\hline 2.200 & & & & & & & 630 & 152 & 224 & 702 & & & & 36 & \\
\hline 2.250 & & & & & & & 112 & 947 & 024 & 14.492 & 92 & & & & \\
\hline 275 & & & & & & & & & & & & & & & \\
\hline 2.400 & & & & & & & 795 & 370 & & 896 & & 67 & & & \\
\hline 2.450 & & 14.279 & 13.318 & 15.630 & 13.145 & & 14.601 & 189 & 11.289 & 709 & 370 & 502 & 926 & & \\
\hline 2.475 & & & & & & & & & & & & & & & \\
\hline 2.500 & & & & & & & 14.411 & 014 & & & & & & & \\
\hline 2.600 & & & & & 12.606 & & 14.048 & 11.679 & 10.797 & 13.177 & 10.885 & .036 & & & \\
\hline 2.625 & & 117 & 12.671 & 14.963 & 12.521 & 11.608 & 13.960 & 598 & 10.719 & 13.093 & 808 & 9.962 & & & \\
\hline 2.700 & & & & & & & 13.704 & 11.362 & 10.493 & & & & & & \\
\hline 2.750 & & & & & & & & 11.211 & & & & & & & \\
\hline 2.800 & & & 12.087 & & & 11.062 & 13.376 & 11.063 & 10.205 & 12.531 & 10.300 & 9.477 & & 540 & \\
\hline 2.925 & & & 11.703 & 13.949 & & & 12.989 & 10.711 & 669 & 12.159 & 9.967 & 9.159 & .434 & 322 & 548 \\
\hline 3.000 & 14.834 & 12.395 & 11.484 & 13.717 & 11.371 & 10.499 & 12.767 & 10.511 & 9.677 & 11.947 & 9.777 & 8.979 & 11.230 & 9.142 & \\
\hline
\end{tabular}

$\times h=60 \mathrm{~mm} \times 120 \mathrm{~mm}$. The dimensions of the tested models $(1200 \mathrm{~mm} \times 1200 \mathrm{~mm}$ and $1200 \mathrm{~mm} \times 800$ $\mathrm{mm})$ are approximately five times smaller than those in real undercarriage frames.

\subsection{Test Stand}

To carry out the experiment, it was necessary to make a rigid platform (2) (Fig. 5), to which the undercarriage frame (1) is attached. The drilled holes (Ø26 mm) are used for supporting the support brackets (3) and dynamometer (5). Forces at the support D are measured by a dynamometer, due to a deflection at the support $\mathrm{C}$ which is set by the presser with a screwed spindle (4). The values of deflection (displacement) at the support $\mathrm{C}$ are measured with a comparator (6). Possible height deviations of the upper surfaces of the longitudinal and cross girders can be cancelled by means of the support brackets, which have the possibility of adjusting the upper surfaces of the supporting frames, so that they lie in the horizontal plane. It should be noted that normal, hot-rolled UNP100 profiles were used for longitudinal and cross girders in acc. to EN 10025:2005 [18].

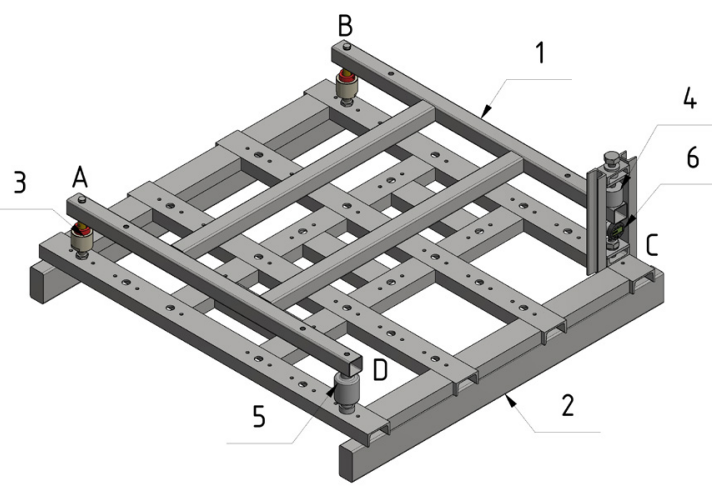

Fig. 5. Connection between the undercarriage frame model (1) and the rigid platform (2) 
The undercarriage frame supports (Fig. 6a) are designed in such a way as to provide turning of the frame ends, thanks to the extension (3) in the shape of a ball. The body (1) with the nuts (4) is firmly attached to the rigid platform (5). The nuts have the role of levelling the upper surface of the undercarriage frame. The separation of the ball rod from the body of the ball-like support (1) is prevented by a conical sleeve (2).

The support $\mathrm{C}$ (Fig. 6b) is compiled of two girders (3) with an upper (1) and a lower traverse (2), thus making a closed type frame. The upper traverse in its middle part has a bushing with a thread, and the presser with a small pitch thread passes through it. By turning the presser (4), via the pad (10), the end of the undercarriage frame (9) at point $C$ is lowered by a given value of clearance $\Delta$.

The lower traverse of the closed frame (2) has an opening for a permanent joint with the rigid platform by means of the threated rod (5), the washer (6) and the nut (7), which, on its upper part, has a drilled hole which serves as the seat of the device (8) for measuring displacements.

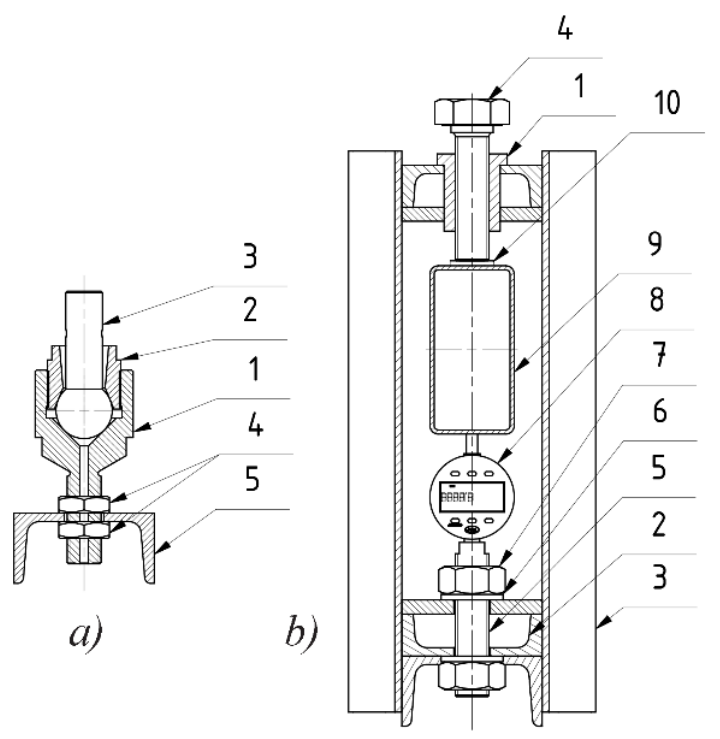

Fig. 6. Ball-like support of the undercarriage frame and the presser with a screwed spindle

\subsection{Testing Procedures}

Registration of force at the support is provided using the force transducer 5, Flintec RC3D30 (with a capacity of $300 \mathrm{kN}$ and sensitivity $2 \%$ ) and alphanumeric display 10 (Fig. 7). Displacement of the girder is registered by the standard dial indicator Mitutoyo 2046SB (range $10 \mathrm{~mm}$, accuracy \pm 13 $\mu \mathrm{m}$, graduation $\pm 0.01 \mathrm{~mm}$ ). To obtain accurate measurement results, the testing of the elastic material behaviour of the model and calibration procedure of dial indicator are performed. The girder is exposed by setting the displacement of the support $\mathrm{C}$, which is entered manually for $3 \mathrm{~mm}$. The procedure is repeated several times after which the girder is completely unloaded. That displacement which acts on the force converter, whose intensity is read on the alphanumeric display.

All mentioned activities show that a model of undercarriage frame exhibits elastic material behaviour. Displacements $\Delta_{C}$ (deflection at the support C) were set with a step of $0.5 \mathrm{~mm}$. Measurements were performed on the four models of undercarriage frames:

1. $l \times L=1200 \mathrm{~mm} \times 1200 \mathrm{~mm}, l_{2}=400 \mathrm{~mm}$, $b \times h \times \delta=60 \mathrm{~mm} \times 60 \mathrm{~mm} \times 2.8 \mathrm{~mm}(k=1)$

2. $l \times L=1200 \mathrm{~mm} \times 1200 \mathrm{~mm}, l_{2}=400 \mathrm{~mm}$, $b \times h \times \delta=60 \mathrm{~mm} \times 120 \mathrm{~mm} \times 2.8 \mathrm{~mm}(k=2)$

3. $l \times L=1200 \mathrm{~mm} \times 800 \mathrm{~mm}, l_{2}=400 \mathrm{~mm}$, $b \times h \times \delta=60 \mathrm{~mm} \times 60 \mathrm{~mm} \times 2.8 \mathrm{~mm}(k=1)$

4. $l \times L=1200 \mathrm{~mm} \times 800 \mathrm{~mm}, l_{2}=400 \mathrm{~mm}$, $b \times h \times \delta=60 \mathrm{~mm} \times 120 \mathrm{~mm} \times 2.8 \mathrm{~mm}(k=2)$

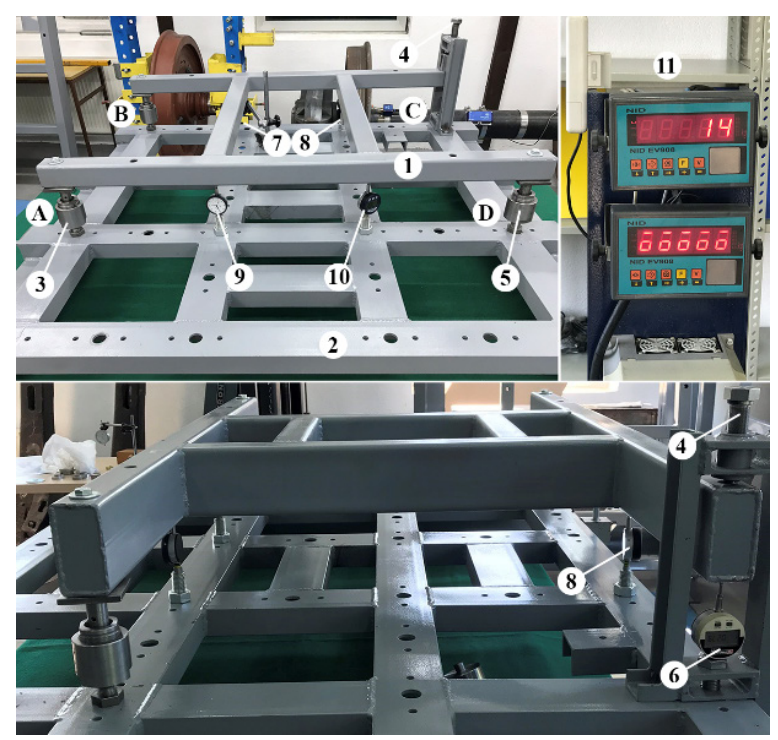

Fig. 7. Test stand: 1 frame model, 2 rigid platform, 3 ball-like support, 4 presser; 5 force transducer, 6 to 10 comparator; 11 alphanumeric display

Comparators 7 to 10 are used for some additional deflection measurements and are not included in this research. The testing procedure for all models is repeated 5 times, whereas the repeatability of results for displacements is $\pm 0.01 \mathrm{~mm}$. The final value was obtained as the mean of the measured sizes. 


\subsection{Measurement Results}

The measured values of force $X_{1}$ at the support $\mathrm{D}$ for all four tested models are shown in Table 4. These measurements were taken for the stepped deflection in support $\mathrm{C}(\Delta=0.5 \mathrm{~mm}, 1.0 \mathrm{~mm}, 1.5 \mathrm{~mm}$ and $2.0 \mathrm{~mm})$.

Table 4. Values of additional force at the supports $D$ for test models with $k=1$

\begin{tabular}{lllll}
\hline$\Delta[\mathrm{mm}]$ & 0.5 & 1.0 & 1.5 & 2.0 \\
\hline$X_{1}{ }^{\prime}[\mathrm{N}]$ & 32 & 64 & 96 & 128 \\
\hline$X_{1}[\mathrm{~N}]$ & 26 & 50 & 74 & 101 \\
\hline \multicolumn{5}{c}{$l \times L=1200 \mathrm{~mm} \times 1200 \mathrm{~mm}}$, \\
$b \times h \times \delta=60 \mathrm{~mm} \times 60 \mathrm{~mm} \times 2.8 \mathrm{~mm}$ \\
\\
$l \times L^{\prime}=1200 \mathrm{~mm} \times 800 \mathrm{~mm} ; k_{1}=1, \varepsilon=1$ \\
\hline
\end{tabular}

Table 5. Values of additional force at the supports $D$ for test models with $k=2$

\begin{tabular}{lcccc}
\hline$\Delta[\mathrm{mm}]$ & 0.5 & 1.0 & 1.5 & 2.0 \\
\hline$X_{1}{ }^{\prime}[\mathrm{N}]$ & 110 & 224 & 325 & 431 \\
\hline$X_{1}[\mathrm{~N}]$ & 85 & 172 & 249 & 350 \\
\hline \multicolumn{5}{c}{$l \times L=1200 \mathrm{~mm} \times 1200 \mathrm{~mm}}$, \\
$b \times h \times \delta=60 \mathrm{~mm} \times 120 \mathrm{~mm} \times 2.8 \mathrm{~mm}$ \\
$l \times L^{\prime}=1200 \mathrm{~mm} \times 800 \mathrm{~mm} ; k_{2}=2, \varepsilon=1$ \\
\hline
\end{tabular}

The analysis of the measurement results presented in Tables 4 and 5 provides the following dependences:

- The ratio of the additional forces $X_{1}{ }^{\prime} / X_{1}$ at the support $\mathrm{D}$, during the change of the coefficient $k\left(k_{1}=1\right.$ and $\left.k_{2}=2\right)$, for both values of length is within the range between 3.27 and 3.50; the calculation result of the obtained theoretical dependence from Eq. (14) is 3.32 .

- The ratio of the additional forces $X_{1}{ }^{\prime} / X$ at the support $\mathrm{D}$, during the change of distance $L=1200$ $\mathrm{mm}$ to $L^{\prime}=800 \mathrm{~mm}$, for both values of parameter $\mathrm{k}$ is within the range between 1.23 and 1.31; the calculation result of the obtained theoretical dependence from Eq. (15) is 1.31.

The differences between the numerical and experimental results are less than $6 \%$. These differences relate to the approximation of moments of inertia and neglecting the influence of the coefficient $\varepsilon$.

\section{CONCLUSION}

The theoretical and experimental analysis of the influences of geometrical parameters on the value of additional forces at the supports of undercarriage frames indicates the following conclusions:
- The ratio between the bending moment of inertia and the torsional moment of inertia of the boxlike section with unique plate thickness depends on the height/width ratio $k$ as defined in Eq. (10).

- As a consequence of the aforementioned, the ratio of bending stiffness and torsional stiffness can be defined by Eq. (11).

- The relation between the force ratio $X_{1(j)} / X_{1(i)}$ and the change of height/width coefficient ratio $k_{j} / k_{i}$ is defined by Eq. (14).

- The relation between the force ratio $X_{1(j)} / X_{1(i)}$ and the change of length ratio $L_{i} / L_{j}$ is defined by Eq. (15).

The relative error of mentioned approximations does not exceed $6 \%$ in comparison to test results.

The results of the research considerably simplify optimization methods in the design of carrying structures with box-like girders and make the precondition for further investigation of their influence on the functioning of large diameter bearing.

\section{ACKNOWLEDGEMENTS}

A part of this research is a contribution to the project TR 35038 funded by the Ministry of Education, Science and Technological Development of the Republic of Serbia.

\section{REFERENCES}

[1] Göncz, P., Potočnik, R., Glodež, S. (2013). Computational model for determination of static load capacity of three-row slewing bearings with arbitrary clearances and predefined raceway deformations. International Journal of Mechanical Science, vol. 73, p. 82-92, D0l:10.1016/j.ijmecsci.2013.04.012.

[2] Zupan, S., Prebil, I. (2001). Carrying angle and carrying capacity of a large single row ball bearing as a function of geometry parameters of rolling contact and supporting structure stiffness. Mechanism and Machine Theory, vol. 36, no. 10, p. 1087-1103, D0l:10.1016/S0094-114X(01)00044-1.

[3] Amasorrain, J.I., Sagartzazu, X., Damián, J. (2003). Load distribution in a four contact-point slewing bearing. Mechanism and Machine Theory, vol. 38, no. 6, p. 479-496, DOI:10.1016/S0094-114X(03)00003-X.

[4] Kania, L., Pytlarz, R., Śpiewak, S. (2018). Modification of the raceway profile of a single-row ball slewing bearing. Mechanism and Machine Theory, vol. 128, p. 1-15, D0l:10.1016/j.mechmachtheory.2018.05.009.

[5] Deng, B., Guo, Y., Zhang, A., Tang, S. (2017). Finite element analysis of thrust angle contact ball slewing bearing. IOP Conference Series: Materials Science and Engineering, vol. 274, art. id. 012096, p. 1-6, D0l:10.1088/1757899X/274/1/012096.

[6] Olave, M., Sagartzazu, X., Damian, J., Serna, A. (2010). Design of four contact-point slewing bearing with a new 
load distribution procedure to account for structural stiffness. Journal of Mechanical Design, vol. 132, no. 2, DOI:10.1115/1.4000834.

[7] Heras, I., Aguirrebeitia, J., Abasolo, M. (2017). Friction torque in four contact point slewing bearings: Effect of manufacturing errors and ring stiffness. Mechanism and Machine Theory, vol. 112, p. 145-154, D0l:10.1016/j. mechmachtheory.2017.02.009.

[8] He, P., Liu, R., Hong, R., Wang, H., Yang, G., Lu, C. (2018). Hardened raceway calculation analysis of a three-row roller slewing bearing. International Journal of Mechanical Sciences, vol. 137, p. 133-144, D0l:10.1016/j.jijmecsci.2018.01.021.

[9] Smolnicki, T., Stanco, M., Pietrusiak, D. (2013). Distribution of loads in the large size bearing-problems of identification. Tehnički vjesnik - Technical Gazette, vol. 20, no. 5, p. 831-836.

[10] Jerman, B., Hladnik, J., Resman, F., Landschützer, C. (2018). Optimization of the support structure of large axial-radial bearing of overhead type manipulator. FME Transactions, vol. 46, no. 3, pp. 386-391, D0I:10.5937/fmet1803386J.

[11] Chen, G., Wang, C., Xiao, Z. (2016). Effects of supporting Structure and bolt connection on the fatigue life and carrying capacity of a slewing bearing. Proceedings of the Institution of Mechanical Engineers, Part J: Journal of Engineering Tribology, vol. 231, no. 6, p. 1-17, Dol:10.1177/1350650116677606.

[12] Duval, R., Bannebach, J., Blasiak, J., Guelbi, A. (2018). Modelling fatigue behavior of slewing rings in crane structures.
Identification of influencing parameters on local stresses and fatigue damage calculations. Procedia Engineering, vol. 213, p. 323-334, DOI:10.1016/j.proeng.2018.02.033.

[13] He, P., Hong, R., Wang, H., Lu, C. (2018). Fatigue life analysis of slewing bearings in wind turbines. International Journal of Fatigue, vol. 111, p. 233-242, D0l:10.1016/j. ijfatigue.2018.02.024.

[14] Pietrusiak, D., Smolnicki, T., Stanńco, M. (2017). The influence of superstructure vibrations on operational loads in the undercarriage of bulk material handling machine. Archives of Civil and Mechanical Engineering, vol. 17, no. 4, p. 855-862, DOI:10.1016/j.acme.2017.03.001.

[15] Maslak, P., Przybylek, G., Smolnicki, T. (2017). Comparison of selected methods for the determination of the center of gravity in surface mining machines. Materials Today: Proceedings, vol. 4, no. 5, p. 5877-5882, D0l:10.1016/j.matpr.2017.06.062.

[16] Gašić, M., Savković, M., Bulatović, R. (2011). Optimization of trapezoidal cross section of the truck crane boom by Lagrange's multipliers and by differential evolution algorithm (DE). Strojniški vestnik - Journal of Mechanical Engineering, vol. 57, no. 4, p. 304-312, D0l:10.5545/sv-jme.2008.029.

[17] Karnovsky, I.A., Lebed, O. (2010). Advanced Methods of Structural Analysis, Springer New York, London.

[18] EN 10025:2005. Hot Rolled Products of Structural Steels - Part 1: General Technical Delivery Conditions. European Committee for Standardization, Brussels., D0l:10.3403/03152972. 